\title{
Aldose Reductase Inhibitors from the Fruiting Bodies of Ganoderma applanatum
}

\author{
Sanghyun Lee, Sang Hee Shim, Ju Sun Kim, Kuk Hyun Shin, and Sam Sik Kang* \\ Natural Products Research Institute and College of Pharmacy, Seoul National University; 28 Yungun-dong, Jongno-gu, \\ Seoul 110-460, Korea. Received December 6, 2004; accepted January 24, 2005
}

The isolation and characterization of rat lens aldose reductase (RLAR) inhibitors from the fruiting bodies of Ganoderma applanatum were conducted. Among the extracts and fractions from $G$. applanatum tested, the $\mathrm{MeOH}$ extract and EtOAc fraction were found to exhibit potent RLAR inhibition in vitro, their $\mathrm{IC}_{50}$ being 1.7 and $0.8 \mu \mathrm{g} / \mathrm{ml}$, respectively. From the active EtOAc fraction, seven compounds with diverse structural moieties were isolated and identified as D-mannitol (1), 2-methoxyfatty acids (2), cerebrosides (3), daucosterol (4), 2,5-dihydroxyacetophenone (5), 2,5-dihydroxybenzoic acid (6), and protocatechualdehyde (7). Among them, protocatechualdehyde (7) was found to be the most potent $\mathrm{RLAR}$ inhibitor $\left(\mathrm{IC}_{50}=0.7 \mu \mathrm{g} / \mathrm{ml}\right)$, and may be useful for the prevention and/or treatment of diabetic complications.

Key words Ganoderma applanatum; Polyporaceae; protocatechualdehyde; aldose reductase activity; diabetic complication

The fruiting bodies of Ganoderma lucidum are a wellknown Chinese medicine that has been used clinically in China, Japan and Korea, for a long time. More than 130 highly oxygenated lanostane-type triterpenoids have been isolated from the fruiting bodies, mycelia and spores of $G$. lucidum, including common fungal steroids derived from ergosterol, some of them exhibiting a bitter taste or useful biological activities. ${ }^{1)}$ Other Ganoderma spp. have also been used in traditional medicine for the treatment of cancer, hypertension and chronic bronchitis, and as a tonic or sedative in China, Japan and Korea. ${ }^{2,3)}$ In our continuing search for the bioactive principles from crude drugs, the extracts and fractions of G. applanatum were evaluated, particularly in relation to their inhibitory effects on rat lens aldose reductase (RLAR). Here, the effects of compounds isolated from $G$. applanatum on RLAR activity in vitro are described.

\section{MATERIALS AND METHODS}

Plant Material The fruiting bodies of Ganoderma applanatum (LeYss. ex Fr.) Karst. (Polyporaceae) were provided by St. Clair Milk and Grocery (Niagara Falls, Canada) in March 2002. The botanical identification was made by Mr. Gregory J. Belmore (Ministry of Natural Resources, Ontario, Canada). A voucher specimen (No. 2002-02) is deposited in the Herbarium of our Institute.

Extraction and Isolation The ground fruiting bodies $(2.1 \mathrm{~kg})$ of $G$. applanatum were extracted with $\mathrm{MeOH}(3$ $1 \times 5)$ under reflux to give an extract $(85 \mathrm{~g})$. The $\mathrm{MeOH}$ extract was suspended in water and successively partitioned with $n$-hexane, dichloromethane, ethyl acetate and $n$-butanol, to yield $15,25,30$ and $15 \mathrm{~g}$ fractions, respectively. The precipitate from the EtOAc fraction was crystallized from $\mathrm{MeOH}$ to yield mannitol $(\mathbf{1}, 35 \mathrm{mg})$. The filtrate from the EtOAc extract $(30 \mathrm{~g})$ underwent silica gel chromatography with hexane-EtOAc-MeOH $(10: 3: 1)$ as the eluent, to afford 15 fractions (EA01-EA15). Fraction EA01 was crystallized from $\mathrm{MeOH}$ to yield 2-methoxyfatty acid (2,10 mg). Fraction EA03 was separated by column chromatography with $\mathrm{CHCl}_{3}-\mathrm{MeOH}-\mathrm{H}_{2} \mathrm{O}(7: 1: 0.5)$ as the eluent, to afford a cerebroside $(3,5 \mathrm{mg})$ and daucosterol $(4,6 \mathrm{mg})$. Fraction EA04 was treated in the same way as EA03, yielding a cere- broside $(3,12 \mathrm{mg})$. Fraction EA05 was applied to silica gel column, with hexane-EtOAc $(5: 8)$ as the eluent, to afford 2,5-dihydroxyacetophenone $(5,5 \mathrm{mg})$. Fraction EA06 was further purified on the same silica gel column, with tolueneEtOAc-HOAc $(5: 3: 1)$ as the eluent, yielding 2,5-dihydroxybenzoic acid $(6,7 \mathrm{mg})$. Fraction EA07 was similarly subjected to a silica gel column, with toluene-EtOAc-HOAc $(2.5: 1: 0.5)$ as the eluent, to yield protocatechualdehyde $(7$, $2 \mathrm{mg}$ ). The purity of each isolate was $>95 \%$. GC analysis of 2 revealed it was composed of $\mathrm{C}_{22}-\mathrm{C}_{25}$ fatty acids (major $\mathrm{C}_{24}: 59 \%$ ). However, the fatty acid moiety of 3 was composed of $\mathrm{C}_{16}, \mathrm{C}_{17}$ (major), and $\mathrm{C}_{18}$.
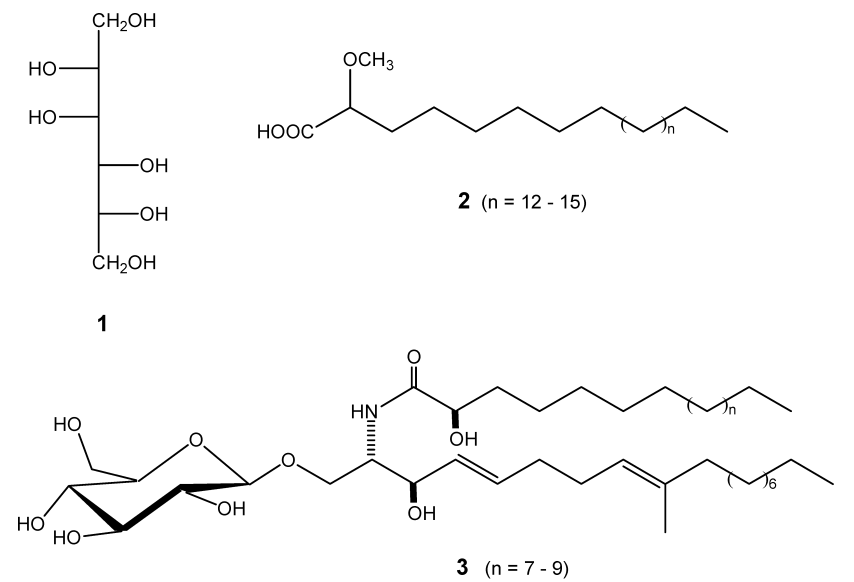<smiles>[R]O[R]=O</smiles>

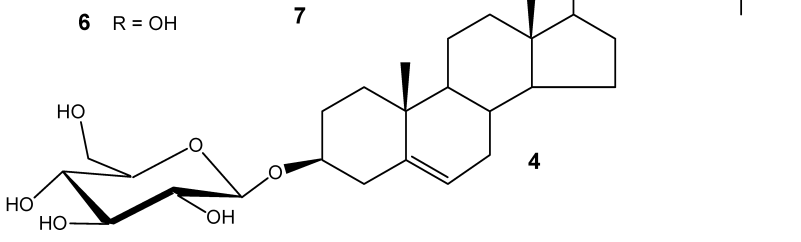

Fig. 1. Structures of Compounds $\mathbf{1}-\mathbf{7}$ 
Chemicals DL-Glyceraldehyde, sodium phosphate and adenine dinucleotide phosphate reduced form (NADPH) were purchased from Sigma Chem. Co. (St. Louis, MO, U.S.A.). All other chemicals and reagents were analytical grade and commercially available.

AR Activity in Vitro Rat lenses were removed from Sprague-Dawley rats weighing $250-280 \mathrm{~g}$ and frozen until use. The supernatant fraction of the rat lens homogenate was prepared according to the procedures of Hayman and $\mathrm{Ki}$ noshita. ${ }^{4)}$ Partially purified enzyme was routinely used to test for enzyme inhibition. The partially purified material was separated into $1.0 \mathrm{ml}$ aliquots and stored at $-40^{\circ} \mathrm{C}$. Rat lenses were homogenized and centrifuged at $12000 \boldsymbol{g}$ and the supernatant was used as an enzyme source. AR activity was assayed spectrophotometrically by measuring the decrease in the absorption of NADPH $(16 \mathrm{~mm})$ at $340 \mathrm{~nm}$ over a $5 \mathrm{~min}$ period, with DL-glyceraldehyde as the substrate. ${ }^{5)}$ The concentrations of the inhibitors producing $50 \%$ inhibition of the enzyme activity $\left(\mathrm{IC}_{50}\right)$ were calculated from the least-squares regression line of the logarithmic concentrations plotted against the remaining activity.

\section{RESULTS AND DISCUSSION}

The effects of the $\mathrm{MeOH}$ extract, the water extract, and the various fractions from $G$. applanatum were estimated with the RLAR enzyme, using DL-glyceraldehyde as a substrate. The inhibitory potencies and $\mathrm{IC}_{50}$ values on the RLAR enzyme were estimated. As shown in Tables 1 and 2, the $\mathrm{IC}_{50}$ values of the $\mathrm{MeOH}$ and the water extracts were determined to be 1.7 and $8.7 \mu \mathrm{g} / \mathrm{ml}$, respectively, while that of TMG, a known AR inhibitor, ${ }^{6}$ was $0.5 \mu \mathrm{g} / \mathrm{ml}$. To evaluate the AR inhibitory compounds from $G$. applanatum, activity-guided fractionation was carried out and their effects on RLAR were tested. The EtOAc fraction from the $\mathrm{MeOH}$ extract was found to exhibit the strongest RLAR inhibitory activity, its $\mathrm{IC}_{50}$ being $0.8 \mu \mathrm{g} / \mathrm{ml}$.

The active EtOAc fraction was subjected to repeated silica gel chromatography yielding seven compounds. They were identified as D-mannitol (1), ${ }^{7}$ 2-methoxyfatty acids (2), ${ }^{8,9)}$ cerebrosides (3) ${ }^{10-13)}$ daucosterol (4), ${ }^{14)}$ 2,5-dihydroxyacetophenone (5), ${ }^{15)}$ 2,5-dihydroxybenzoic acid (6) ${ }^{16)}$ and protocatechualdehyde $(7)^{17,18)}$ by spectral analysis and comparison of their spectroscopic data with those reported. All of these compounds were isolated for the first time from the fruiting bodies of G. applanatum. All compounds were tested for their effects on RLAR, and the results are summarized in Table 3 . The results show that only protocatechualdehyde (7) showed significant inhibitory activity towards AR, with an $\mathrm{IC}_{50}$ of $0.7 \mu \mathrm{g} / \mathrm{ml}$, which is equivalent to that of the positive control TMG $\left(\mathrm{IC}_{50}=0.6 \mu \mathrm{g} / \mathrm{ml}\right)$. The results suggest that two simple phenolic compounds $(\mathbf{5}, \mathbf{6})$ having 2,5-dihydroxy benzene moieties exhibit somewhat lower potencies than that carrying a catechol moiety as suggested in flavonoids and related compounds for AR inhibitory activity. ${ }^{19)}$ We concluded that the observed activity in the crude EtOAc extract $\left(\mathrm{IC}_{50}=0.8 \mu \mathrm{g} / \mathrm{ml}\right)$ was probably attributable to the contribution of the inhibitory effects of unknown polyphenols or other compounds present and/or the synergistic effect of individual AR inhibitory constituents when tested in the form of a complex mixture. It has been acknowledged that plant-de-
Table 1. Inhibitory Effects of the $\mathrm{MeOH}$ and Water Extracts on the RLAR

\begin{tabular}{lccc}
\hline \hline Extract & $\begin{array}{c}\text { Concentration } \\
(\mu \mathrm{g} / \mathrm{ml})\end{array}$ & $\begin{array}{c}\text { Inhibition } \\
(\%)\end{array}$ & $\begin{array}{c}\mathrm{IC}_{50} \\
(\mu \mathrm{g} / \mathrm{ml})\end{array}$ \\
\hline TMG & 10 & 94.7 & 0.5 \\
& 1 & 81.7 & \\
MeOH extract & 0.1 & 10.8 & 1.7 \\
& 100 & 99.9 & \\
Water extract & 10 & 80.3 & 8.7 \\
& 1 & 39.8 & \\
& 10 & 98.5 & 56.5 \\
\hline
\end{tabular}

Inhibition rates were calculated as percentages with respect to the control value. TMG: tetramethylene glutaric acid.

Table 2. Inhibitory Effects of the Various Fractions on the RLAR

\begin{tabular}{lccc}
\hline \hline Fraction & $\begin{array}{c}\text { Concentration } \\
(\mu \mathrm{g} / \mathrm{ml})\end{array}$ & $\begin{array}{c}\text { Inhibition } \\
(\%)\end{array}$ & $\begin{array}{c}\mathrm{IC}_{50} \\
(\mu \mathrm{g} / \mathrm{ml})\end{array}$ \\
\hline \multirow{2}{*}{ TMG } & 10 & 92.7 & 0.5 \\
& 1 & 68.7 & \\
$n$-Hexane & 0.1 & 19.8 & 5.0 \\
& 100 & 91.1 & \\
$\mathrm{CH}_{2} \mathrm{Cl}_{2}$ & 10 & 52.7 & 1.7 \\
& 1 & 32.7 & \\
& 10 & 87.2 & 0.8 \\
EtOAc & 5 & 68.2 & \\
& 1 & 41.2 & 1.3 \\
& 10 & 90.5 & \\
& 1 & 65.8 & 34.7 \\
& 0.5 & 94.4 & \\
& 10 & 37.7 & \\
& 1 & 35.4 & \\
& 0.5 & &
\end{tabular}

Inhibition rates were calculated as percentages with respect to the control value TMG: tetramethylene glutaric acid.

Table 3. Inhibitory Effects of Compounds $\mathbf{1}-\mathbf{7}$ on the RLAR

\begin{tabular}{cccc}
\hline \hline Compound & $\begin{array}{c}\text { Concentration } \\
(\mu \mathrm{g} / \mathrm{ml})\end{array}$ & $\begin{array}{c}\text { Inhibition } \\
(\%)\end{array}$ & $\begin{array}{c}\mathrm{IC}_{50} \\
(\mu \mathrm{g} / \mathrm{ml})\end{array}$ \\
\hline TMG & 10 & 91.5 & 0.6 \\
& 1 & 62.9 & \\
$\mathbf{1}$ & 0.1 & 18.4 & $>100$ \\
$\mathbf{2}$ & 100 & 2.6 & $>100$ \\
$\mathbf{3}$ & 100 & 0.73 & 30.0 \\
& 100 & 94.3 & \\
& 50 & 66.3 & $>100$ \\
$\mathbf{4}$ & 10 & 11.4 & 39.4 \\
$\mathbf{5}$ & 100 & 1.0 & \\
$\mathbf{6}$ & 100 & 27.5 & 0.7 \\
& 100 & 83.2 & \\
$\mathbf{7}$ & 50 & 53.5 & 6.9 \\
& 10 & 89.7 & \\
& 10 & 77.4 & \\
& 5 & 46.7 & \\
\hline
\end{tabular}

Inhibition rates were calculated as percentages with respect to the control value TMG: tetramethylene glutaric acid.

rived extracts and phytochemicals are potential alternatives to synthetic inhibitors against AR. ${ }^{19,23,27)}$ Currently, the compounds isolated from plants as AR inhibitors are classified as flavonoids,${ }^{19-26)}$ stilbenes,${ }^{19)}$ terpenoids ${ }^{21)}$ ellagic acid and its derivatives, ${ }^{28)}$ and alkaloids. ${ }^{29)}$ 
The present study was carried out in a search for new potential AR inhibitors from the fruiting bodies of $G$. applanatum, and cerebrosides (3), 2,5-dihydroxybenzoic acid (6) and protocatechualdehyde (7) were isolated as active principles which may be useful for the treatment of diabetic complications.

Acknowledgement This study was supported by a grant from the St. Clair Milk and Grocery (Niagara Falls, Canada).

\section{REFERENCES}

1) Kim H. W., Kim B. K., Int. J. Med. Mushr., 1, 121-138 (1999).

2) Ming D., Chilton J., Fogarty F., Towers G. H. N., Fitoterapia, 73, $147-152$ (2002).

3) Yoshikawa K., Nishimura N., Bando S., Arihara S., Matsumura E., Katayama S., J. Nat. Prod., 65, 548-552 (2002).

4) Hayman S., Kinoshita J. H., J. Biol. Chem., 240, 877-882 (1965).

5) Sato S., Kador P. F., Biochem. Pharmacol., 40, 1033-1042 (1990).

6) Hutton J. C., Schofield P. J., Williams J. F., Hollows F. C., Biochem. Pharmacol., 23, 2991-2998 (1974).

7) Dominguez X. A., Butruille D., Zamudio A., Reyes C. G., Castillo J. T., Phytochemistry, 11, 2616 (1972).

8) Ayanoglu E., Popov S., Kornprobst J. M., Aboud-Bichara A., Djerassi C., Lipids, 18, 830-836 (1983).

9) Carballeira N. M., Pagan M., J. Nat. Prod., 64, 620-623 (2001).

10) Gao J.-M., Hu L., Dong Z.-J., Liu J.-K., Lipids, 36, $521-527$ (2001).

11) Gao J.-M., Sheng J., Yang X., Liu J.-K., Acta Bot. Yun., 23, 385-393 (2001).

12) Mizushina Y., Hanashima L., Yamaguchi T., Takemura M., Sugawara F., Saneyoshi M., Matsukage A., Yoshida S., Sakaguchi K., Biochem. Biophys. Res. Commun., 249, 17-22 (1998).

13) Toledo M. S., Levery S. B., Straus A. H., Suzuki E., Momany M.,
Glushka J., Moulton J. M., Takahashi H. K., Biochemistry, 38, 72947306 (1999).

14) Xu Y. N., Kim J. S., Kang S. S., Son K. H., Kim H. P., Chang H. W., Bae K.-H., Chem. Pharm. Bull., 50, 1124-1125 (2002).

15) Lin C.-N., Huang P.-L., Lu C.-M., Yen M.-H., Wu R.-R., Phytochemistry, 44, 1369-1373 (1997).

16) "Handbook of Proton-NMR Spectra and Data," Vol. 2, Asahi Research Center, ed., Academic Press, Inc., London, 1985, p. 268.

17) Kikuzaki H., Kawai Y., Nakatani N., J. Nutr. Sci. Vitaminol., 47, 167171 (2001)

18) Weber B., Hoesch L., Rast D. M., Phytochemistry, 40, 433-437 (1995).

19) Matsuda H., Morikawa T., Toguchida I., Yoshikawa M., Chem. Pharm. Bull., 50, 788-795 (2002).

20) Shin K. H., Kang S. S., Kim H. J., Shin S. W., Phytomedicine, 1, 145-147 (1994).

21) Shimizu M., Horie S., Arisawa M., Hayashi T., Suzuki S., Yoshizaki M., Kawasaki M., Terashima S., Tsuji H., Wada S., Ueno H., Morita N., Berganza L. H., Ferro E., Basualdo I., Chem. Pharm. Bull., 35, 1234-1237 (1987).

22) Aida K., Tawata M., Shindo H., Onaya T., Sasaki H., Yamaguchi T., Chin M., Mitsuhashi H., Planta Med., 56, 254-258 (1990).

23) Haraguchi H., Ohmi I., Sakai S., Fukuda A., J. Nat. Prod., 59, 443445 (1996).

24) Haraguchi H., Kanada M., Fukuda A., Naruse K., Okamura N., Yagi A., Planta Med., 64, 68-69 (1998).

25) Yoshikawa M., Shimada H., Nishida N., Li Y., Toguchida I., Yamahara J., Matsuda H., Chem. Pharm. Bull., 46, 113-119 (1998).

26) Haraguchi H., Hayashi R., Ishizu T., Yagi A., Planta Med., 69, 853855 (2003).

27) Matsuda H., Murakami T., Yashiro K., Yamahara J., Yoshikawa M., Chem. Pharm. Bull., 47, 1725-1729 (1999).

28) Ueda H., Kuroiwa E., Tachibana Y., Kawanishi K., Ayala F., Moriyasu M., Phytomedicine, 11, 652-656 (2004).

29) Lee H.-S., J. Agric. Food Chem., 50, 7013-7016 (2002). 